\title{
Prospective Memory Assessment, before and after the Use of Concentrated Extract of Soy, in Postmenopausal Women Complaining of Memory Impairment
}

\author{
Lucia Helena Laprano Vieira, Teresa Raquel Embiruçu de Araújo, Mauro Abi Haidar, Ivaldo Silva
}

Gynecological Endocrinology, Department of Gynecology, Federal University of São Paulo (UNIFESP), São Paulo, Brazil.

Email: lucia.andalo@terra.com.br, ivaldo.toco@epm.br

Received August $3^{\text {rd }}, 2013$; revised September $1^{\text {st }}, 2013$; accepted October $1^{\text {st }}, 2013$

Copyright (C) 2013 Lucia Helena Laprano Vieira et al. This is an open access article distributed under the Creative Commons Attribution License, which permits unrestricted use, distribution, and reproduction in any medium, provided the original work is properly cited.

\begin{abstract}
Objective: To evaluate the performance of a sample of postmenopausal women complaining of decline of prospective memory, undergoing therapy with concentrated extract of soy (CES) for six months, through specific neuropsychological assessment, developed for this purpose. Materials and Methods: A randomized and double-blind study was with 90 women, 12-month amenorrhea, 40 years to 65 years and body mass index (BMI) above $30 \mathrm{~kg} / \mathrm{m}^{2}$, whose complaints were reduction of cognitive efficiency. The participants were randomly divided into two treatment groups: Group I-received one capsule of $150 \mathrm{mg}$ extract of soy, with $60 \mathrm{mg}$ isoflavones orally/day; Group II—received one capsule placebo, for six months. All participants underwent a detailed interview, the MMSE, depression scale, and as they were being included in the study, self-perception scales and neuropsychological tests before and after six months of treatment. For analysis purposes, we applied the ANOVA and t-student tests. Results: Our results suggest a possible positive effect regarding the improvement in verbal fluency and executive function tasks of planning and mental flexibility, in women undergoing therapy with concentrated extract of soy in postmenopause. There was no correlation between prospective memory and cognitive performance, and there were only intensity scores of the depressive symptoms. Conclusion: Isoflavones act favorably on the cognitive function, amongst all functions, only on verbal memory and executive function tasks of planning and mental flexibility. The others showed no signs of improvement. We concluded that concentrated extract acts only on some cognitive functions.
\end{abstract}

Keywords: Menopausal Transition; Postmenopausal; Isoflavones; Prospective Memory; Neuropsychology

\section{Introduction}

Menopause is defined as the permanent cessation of menstruation, and normally occurs around the age of 40 [1]. Estrogen deficiency of this phase is associated with vasomotor symptoms, trophic changes, bone loss, cardiovascular disease $[2,3]$, psychological disorder and decline in terms of cognitive effectiveness [4-6].

Regarding the reduction of the effectiveness of cognitive functioning after menopause, about $60 \%$ of women in the menopausal transition have worsened memory, showing difficulty in remembering words and numbers, and evoking previous situations and intentions that must be performed in the future, thus having complaints of difficulty in concentrating very frequently [7].

The memory is, however, a complex working system and difficulties in remembering intentions that should be turned into actions in the future, within a short period of time or longer, are referred to as prospective memory failure (PM). Difficulties in recalling previous events and situations are called retrospective memory failures (RM) [8].

The prospective memory is widely used in daily activities such as work, study or social life and is fully integrated in the social relations of daily life, and prospective memory-related failures, as in the case of forgetting an appointment may have extremely negative social consequences $[9,10]$.

For several decades, the use of hormone therapy was considered as the ideal treatment for climacteric symptoms; however, the controversy over its hormonal effects 
has caused a significant increase in the search for natural forms of treatment. There is evidence demonstrating that the use of soy-derived isoflavones might be a good alternative for the treatment of various symptoms associated with menopause transition, as well as for patients with contraindications to conventional TH [11-13].

Although several studies have demonstrated the influence of isoflavones on cognitive performance, the results are still contradictory. A review by MacReady et al. (2009) [14], about the effects of concentrated extract of soybean (ECS) on cognition in postmenopausal women, showed discrepancies in the results of different studies, with justifications pointing to variations in sample size, composition of phytoestrogens, time management, and study design, suggesting the need for further studies to understand the influence of the long-term effects of soy isoflavones on cognitive functioning, because of the high prevalence of complaints related to memory difficulties, reported in the postmenopausal period.

The aim of our study was to evaluate the performance of a sample of postmenopausal women complaining of decay in prospective memory, undergoing therapy with concentrated extract of soy and possible correlations with scales of self-perception and mood indicators.

\section{Materials and Methods}

The study group consisted of 90 postmenopausal women assisted in the Menopausal and Postmenopausal Transition sector, regarding the discipline of Gynecological Endocrinology, Department of Gynecology, Federal University of São Paulo, Paulista School of Medicine (UNIFESP-EPM), from May 2009 to May 2013. This project has been approved by the Ethics Committee of the Federal University of São Paulo/São Paulo hospital, as part of the research project "Effects of isoflavones on sexual response in postmenopausal women". The diagnosis of menopause was based on clinical data, that is, amenorrhea for at least 12 months, confirmed by the increase of gonadotropin, follicle stimulating hormone $(\mathrm{FSH}>40 \mathrm{mIU} / \mathrm{mL})$ and low amounts of estrogen (E2 < $20 \mathrm{ng} / \mathrm{dl}$ ). The patients who met this criteria, complaining of decline in cognitive efficiency, that hadn't undergone previous hormone treatments, and hadn't made use of herbal or diet rich in soy foods, for three months, were selected to participate in the study.

Patients suffering from cognitive impairment, according to the MMSE Mini-Mental State Examination criteria, having scored 36 or more on the Beck Depression Inventory, aged less than 40 years of age and more than 65 years of age, body mass index (BMI) greater than 30 $\mathrm{kg} / \mathrm{m}^{2}$ or contraindication to estrogen therapy haven't been included.

Patients were randomly divided into two groups (the choice of treatment was determined by computer program randomized number generator, and just after the end of the study, the researcher knew which group the patient belonged to: Group I-received $150 \mathrm{mg}$ of concentrated extract of soy in the form of a capsule with 60 $\mathrm{mg}$ of total isoflavones orally/day, herbal product, commercialized by the Herbarium Isoflavine laboratory; group II-received a capsule containing inactive substance (placebo). All made use of the medication continuously for six months. The capsules have a white color, thus making it impossible for the researcher and patient to distinguish which one was the substance. All studied patients underwent the routine laboratory exams (Pap smear (maturation index, and hormonal evaluation), transvaginal ultrasonography, mammography), whose results will not be discussed in this paper. In addition, we collected information on the age, weight and height, age, race and time since menopause (Table $\mathbf{1}$ ).

All participants underwent a detailed interview, the MMSE, the depression scale, and as they were being included in the study, they were subjected to the self-

Table 1. Socio-demographic and clinical variables, related to samples of women have been included in the study.

\begin{tabular}{|c|c|c|c|}
\hline & Group I & Group II & (p) \\
\hline & & $\begin{array}{l}\text { Isoflavones } \\
\mathrm{n}=43\end{array}$ & \\
\hline Age (average in years) ${ }^{*}$ & $53.5 \pm 4.07$ & $55.1 \pm 3.81$ & 0.062 \\
\hline $\operatorname{IMC}\left(\mathbf{k g} / \mathbf{m}^{2}\right)^{*}$ & $24.7 \pm 2.65$ & $25.4 \pm 2.71$ & 0.221 \\
\hline $\begin{array}{l}\text { Date of last menstrual period } \\
\qquad \text { (age) }\end{array}$ & $4.2 \pm 2.47$ & $4.4 \pm 2.65$ & 0.819 \\
\hline Previo & $61 \%(25)$ & $69.8 \%(30)$ & 0.492 \\
\hline \multicolumn{2}{|c|}{ Maritual status $^{* *}$ (frequency \%) } & & 0.227 \\
\hline Married/Stable relationship (n) & $65.9 \%(27)$ & $81.4 \%(35)$ & \\
\hline Divorced/separated (n) & $24.4 \%(10)$ & $11.6 \%(5)$ & \\
\hline Single/widow (n) & $9.8 \%(4)$ & $7 \%(3)$ & \\
\hline Schooling (frequency) & & & 0.774 \\
\hline From 0 to 3 years of age (n) & 0 & 0 & \\
\hline From 4 to 8 years of age (n) & $14.6 \%(6)$ & $20.9 \%(9)$ & \\
\hline From 9 to 11 years of age (n) & $39 \%(16)$ & $37.2 \%(16)$ & \\
\hline Above 12 years of age $(n)$ & $46.3 \%(19)$ & $41.9 \%(18)$ & \\
\hline Profession (frequency) & & & 0.696 \\
\hline Economically active (n) & $58.5 \%(24)$ & $53.5 \%(23)$ & \\
\hline Retired (n) & $19.5 \%(8)$ & $16.3 \%(7)$ & \\
\hline Hosewife/student (n) & $22 \%(9)$ & $30.2 \%(13)$ & \\
\hline${ }^{*}$ Fish & $s$ exact test & & \\
\hline
\end{tabular}


perception scales and neuropsychological tests in the beginning of and after the six months of treatment.

\subsection{Evaluation of Prospective Memory}

The main objective of this study was to evaluate the prospective memory; however, we have used neuropsychological tests to assess various cognitive domains such as intellectual efficiency, attention, memory, language and executive function, to understand other areas of cognitive whose deficits could have a say in the performance tests of prospective memory.

The prospective memory was assessed with two scales of self-perception: Subjective Perception Memory Test (MAC-Q) [15], used to assess memory complaints related to five everyday situations and Prospective and Retrospective Memory Questionnaire (PRMQ) [8], elaborated to assess failure of prospective memory (PM) and retrospective memory $(\mathrm{RM})$ in patients with cognitive impairment, clinical and healthy populations.

\subsection{Neuropsychological Evaluation}

Neuropsychological assessment tests that were used followed the protocol widely used for cognitive research: attention, language, executive functions and memory. The test battery included measures of language and executive function (Semantic Verbal Fluency Test-SVF); attention (A and B Trails, codes), memory (the memory list words TMLP), executive functions (Stroop Color Test and Forward and Backward Digits)

\subsection{Sample Size and Statistical Analysis}

Initially we calculated the sample size with the aid of the computer program. The required number to estimate an association between adherence to treatment and clinical improvement in postmenopausal women complaining of memory impairment was 45 women. For the treatment of multivariate correlations, a $50 \%$ increase in sample size, with a total number of about 90 women has been proposed. For analysis purposes, we applied the ANOVA and t-Student tests. In all comparisons, it was considered as significant probabilities associated with tests less than 0.05 , i.e., with a maximum of $5 \%$ chance of rejecting the hypothesis of equality when it is true.

\section{Results}

In total, 90 postmenopausal patients, Who met the initial criteria, were included in the study and randomly divided into two groups: Group 1-received $150 \mathrm{mg}$ of concentrated extract of soy in the form of a capsule, with $60 \mathrm{mg}$ of total isoflavones, orally/day group II-received a capsule containing inactive substance (placebo) for six months.

During the study, four patients from the placebo group gave up (one for the sake of weight gain, one by private issues and two for lack of adherence). In the group treated through isoflavones, one patient gave up due to weight gain and lack of adherence. At the end, 84 completed the study as outlined in the sample study scheme (Figure 1).

In the assessment of sociodemographic and clinical characteristics of patients participating in the study, at the beginning of the treatment, there was no statistically significant difference between the two groups, which demonstrated that they were similar in the pre-treatment (Table 1). The performance results scored in the scales of perception, depression and assessment of cognitive point of view, isoflavone and placebo groups, are widely shown in Table 2.

Regarding performance in the self-perception scales, we found no statistically significant difference $(p<0.05)$ between the groups; however, at the data analysis in order to investigate the reliability of the changes, between pre and post treatment, and the clinical significance of these changes, the isoflavone group had a reliable change

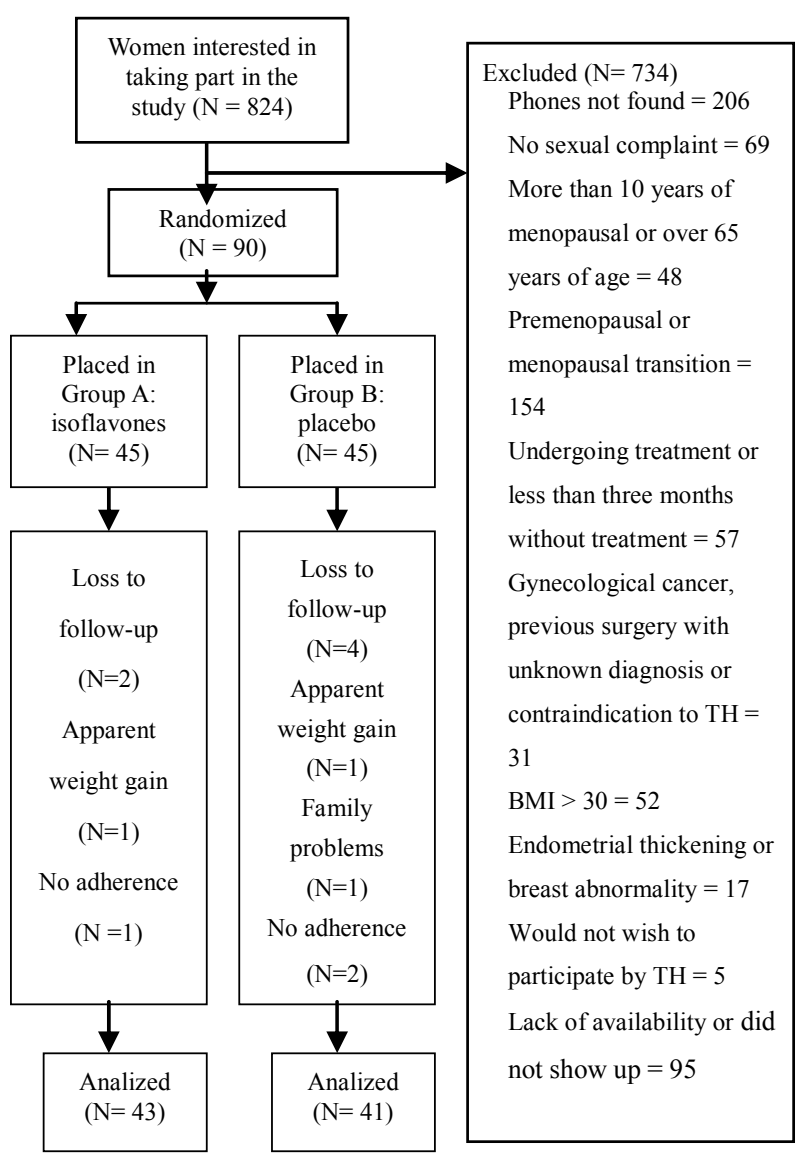

Figure 1. Study sample scheme. 
Table 2. Summary of the overall results of the study of the placebo groups and isoflavones at the first visit (pretreatment) and after 6 months of treatment.

\begin{tabular}{cccc}
\hline & placebo & Isoflavone & value ${ }^{*}$ \\
\hline BDI & $-6.2(11.28)$ & $-7.8(10.10)$ & 0.486 \\
MAC-Q & $-2.3(15.46)$ & $-7.3(17.94)$ & 0.172 \\
OVERALL TOTAL PRMQ & $-2.9(15.94)$ & $-7.3(18.74)$ & 0.250 \\
TRAIL A (seconds) & $-6.7(15.82)$ & $-2.8(21.07)$ & 0.340 \\
TRAIL B (seconds) & $-10.0(27.28)$ & $-8.4(50.91)$ & 0.852 \\
STROOP I & $-1.4(6.95)$ & $-3.6(7.00)$ & 0.146 \\
STROOP II & $-2.2(5.85)$ & $-1.5(7.78)$ & 0.663 \\
STROOP III & $-4.8(10.82)$ & $-4.1(9.20)$ & 0.891 \\
LIST OF WORDS (Total) & $6.7(11.69)$ & $5.9(11.88)$ & 0.764 \\
CODES & $2.4(6.66)$ & $2.5(5.48)$ & 0.973 \\
OD Digits & $-0.9(11.43)$ & $-5.6(13.00)$ & 0.078 \\
OI Digits & $-2.0(14.76)$ & $-0.6(15.04)$ & 0.657 \\
TOTAL OF Digits & $-1.4(8.37)$ & $-3.3(8.98)$ & 0.319 \\
VERBAL FLUENCY & $0.3(2.48)$ & $1.3(1.72)$ & $0.027^{*}$ \\
comparison between groups & & & \\
\hline
\end{tabular}

in the scale of self-reported failures of prospective memory $(\mathrm{p}=0.027)$ (Figure 2$)$.

In the group of isoflavones there was no statistically significant difference $(\mathrm{p}<0.05)$ between prospective memory and performance on neuropsychological tests of controls: Track A $(p=0.340)$, Track B $(p=0.852)$, word list $(\mathrm{p}=0.764)$, Codes subtest $(\mathrm{p}=0.973)$, Stroop I $(\mathrm{p}=$ $0.146)$, Stroop II ( $p=0.663)$, Stroop III ( $p=0.891)$, Total Digits Forward and Backward $(\mathrm{p}=0.319)$. In the verbal fluency test that assesses processing of language and executive function, the isoflavone group had better performance when compared to the control group. $(\mathrm{p}=$ $0.027)$.

The correlation of the scales of self-perception (MACQ, MP and MR) with neuropsychological tests was statistically weak, however there was a positive correlation between the scale that assesses the severity of Beck depressive symptoms with the scale of self-perception PRMQ in Total $(\mathrm{p}=0.001), \mathrm{mp}(\mathrm{p}=0.002)$, and MR $(\mathrm{p} \leq$ $0.001)$.

\section{Discussion}

This study aimed at analyzing the effects of the concentrated extract of soy in the perception of prospective memory, after menopause. We know that cognitive decline is very common in the transition and postmeno-

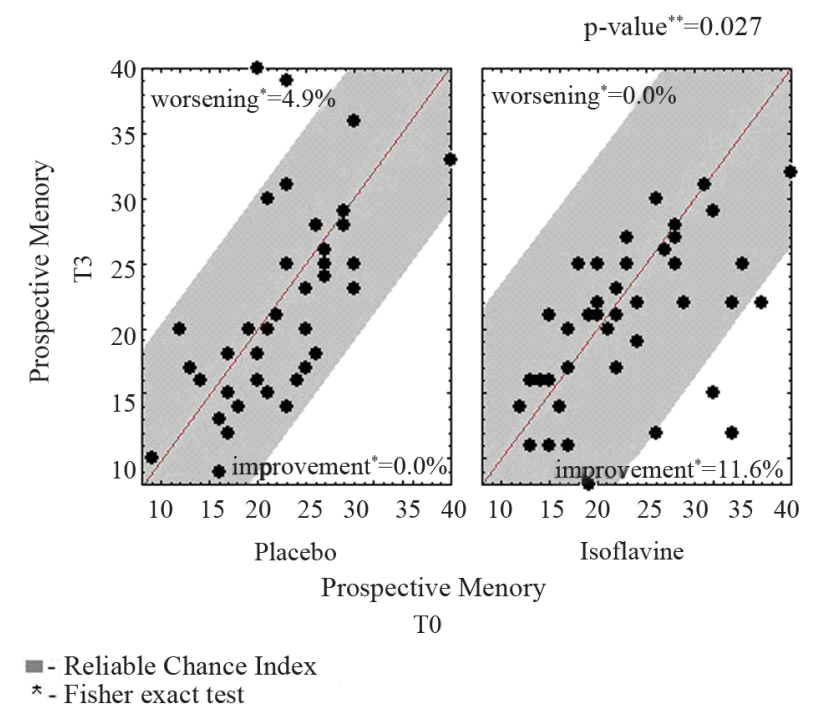

Figure 2. Reliability of the pre- and post-intervention changes on the self-reported prospective memory failures scale.

pause. Several theories attempting to explain the retardation appeared through that stage, and the more likely is the one regarding the reduction of the levels of estrogens, by changing some neurotransmitters and synaptic density in key areas of the central nervous system (CNS) [16].

Investigations on the effects of HT on cognitive functioning revealed positive effects, particularly in verbal memory, verbal fluency, concentration, attention and speed of information processing $[17,18]$.

Our results partially confirm these data and suggest a possible positive effect of isoflavones regarding greater verbal fluency and executive function tasks of planning and mental flexibility, in women undergoing therapy with concentrated extract of soy in postmenopausal.

Our sample showed some important characteristics, such as an average age of 55 years, which can be indicated as a negative factor, since it excludes the possibility of research into the effect of age and frequency of memory failures; however, results reported by Hachul et al. (2009) [19] reported that patients in the early postmenopausal period claimed to have more memory failures compared to women in pre-menopause and during the late postmenopause. Possibly, these subjective memory difficulties reflect a greater perception of cognitive performance that was strongly reflected in the average age of our sample.

Another important demographic characteristic was the average schooling, mostly 9 to 11 years and above 12 years, as well as the highest percentage regarding professions: economically active patients. According to De Lorenzi et al. (2006) [20] as they approach menopause, women bring questions about the physical changes that 
will occur and how to handle them. The higher education not only facilitates access to information about menopause, but also reduces anxiety, which is so common in this phase. The very self-care itself is affected by schooling and is related to the increased demand for medical care at this stage [21].

As for the intensity of depressive symptoms, we observed a reduction in two groups: control and isoflavones, suggesting the existence of a placebo response often reported in clinical trials for the treatment of neuro-vegetative symptoms associated with menopause [22].

With respect to subjective perception of prospective memory, our data indicate that the group receiving isoflavones had better performance, so this improvement was not significant when compared to the placebo group. When we investigate the reliability of the changes between pre- and post-treatment and clinical significance, we found that the isoflavone group showed clinical improvement (perception) after six months of treatment.

In our study, the group of isoflavones performed better on the verbal fluency test when compared to the control group. Verbal fluency tasks have been widely used to assess processing of language and executive function, and our results are consistent with studies by Howes et al. (2004), Kreijkamp-Kaspers et al. (2004) e Ho et al. (2007) [23-25].

Unexpectedly, our data suggest that the placebo group showed significant improvement in tests of selective and divided attention when compared to isoflavones. These results need further studies, and a hypothesis to be raised is that possibly these measures were not sensitive enough to detect improvement in the performance of the function evaluated $[14,17,23,24]$.

The evaluation of immediate memory, storage capacity and recovery, and the memory test of word list (TLMP) showed no differences between the number of words recalled and raised in the two groups. It is noteworthy, that schooling, according to Beeri et al. (2006) [26], may have been a factor positively associated with the outcome of the cognitive performance presented by two groups. Similarly to the previous result, no differences were found in relation to performance in the operational memory, when compared to the placebo group and the group of isoflavones.

There are limitations in our study concerning the selection of instruments for evaluating the performance of prospective memory. According to Mizuno (2001) [9], the methods used to study prospective memory currently involve questionnaires, naturalistic ecological evidence and laboratory studies. Although we've used a questionnaire of quick application and easy understanding, its validity is questioned by the ratio between the direct response and the actual daily routine.
Despite of the updating of self-perception questionnaires and neuropsychological tests, we need more longterm studies, so that they are able to achieve more conclusive evidence of the action of phytoestrogens on cognitive function at the postmenopause.

\section{Acknowledgements}

This work has been supported by CNPq, National Council for Scientific and Technological Development.

\section{REFERENCES}

[1] A. M. Fonseca and H. W. Halbe, "Fisiologia do Climatério," In: Tratado de Ginecologia, 2nd Edition, Roca, São Paulo, 1994, pp. 1237-1242.

[2] C. E. Fernandes, E. C. Baracat and G. R. Lima, "Climatério: Manual de Orientação da FEBRASGO,” Ponto, São Paulo, 2004.

[3] E. C. Baracat and G. R. Lima, "Climatério in: Ginecologia-Manuais, Guia de Medicina Ambulatorial e Hospitalar," Manole, São Paulo, 2005, pp. 339-343.

[4] I. Silva, G. Mor and F. Naftolin, "Estrogen and the Aging Brain," Maturitas, Vol. 38, No. 1, 2001, pp. 95-100. http://dx.doi.org/10.1016/S0378-5122(00)00195-X

[5] A. O. Pedro, A. M. Pinto-Neto, L. Costa-Palva, M. J. Osis and E. Hardy, "Procura de Serviço Médico por Mulheres Climatéricas Brasileiras," Revista de Saúde Pública, Vol. 36, No. 4, 2002, pp. 484-490. http://dx.doi.org/10.1590/S0034-89102002000400015

[6] E. W. Freeman, M. D. Sammel, H. Lin and D. B. Nelson, "Associations of Hormones and Menopausal Status with Depressed Mood in Women with No History of Depression," Archives of General Psychiatry, Vol. 63, No. 4, 2006, pp. 375-382. http://dx.doi.org/10.1001/archpsyc.63.4.375

[7] A. C. J. S. Silva and M. F. S. Sá, "Efeito dos Esteróides Sexuais Sobre o Humor e a Cognição," Revisão da literatura. Revista de Psiquiatria Clínica, Vol. 33, No. 2, 2006, pp. 60-67.

[8] D. Benites and W. B. Gomes, "Translation, Adaptation and Preliminary Validation from Prospective and Retrospective Memory Questionnalre (PRMQ)," PsicoUSF, Vol. 12, No. 1, 2007, pp. 45-54.

[9] S. Mizuno, "Prospective Memory for Future Intentions," Bulletin of Toyo Gakuen University, Vol. 9, No. 1, 2001, pp. 1-11.

[10] P. S. Bisiacchi, V. Tarantino and A. Ciccola, "Aging and Prospective Memory: The Role of Working Memory and Monitoring Processes," Aging Clinical and Experimental Research, Vol. 20, No. 6, 2008, pp. 569-577. http://dx.doi.org/10.1007/BF03324886

[11] C. Kaari, M. A. Haidar, J. M. Soares Júnior, M. G. Nunes, L. G. Quadros and C. Kemp, "Randomized Clinical Trial Comparing Conjugated Equine Estrogens and Isoflavones in Postmenopausal Women: A Pilot Study," Maturitas, Vol. 53, No. 1, 2006, pp. 49-58. 
http://dx.doi.org/10.1016/j.maturitas.2005.02.009

[12] J. Miquel, A. Ramírez Boscá, J. V. Ramírez-Boscá and J. D. Alperi, "Menopause: A Review on the Role of Oxygen Stress and Favorable Effects of Dietary Antioxidants," Archives of Gerontology and Geriatrics, Vol. 42, No. 3, 2006, pp. 289-306. http://dx.doi.org/10.1016/j.archger.2005.08.005

[13] G. Cheng, B. Wilczek, M. Warner, J. A. Gustafsson and B. M. Landgren, "Isoflavone Treatment for Acute Menopausal Symptoms," Menopause, Vol. 14, No. 3, 2007, pp. 468-473. http://dx.doi.org/10.1097/GME.0b013e31802cc7d0

[14] A. L. MacReady, O. B. Kennedy, J. A. Ellis, C. M. Williams, J. P. E. Spencer and L. T. Butler, "Flavonoids and Cognitive Function: A Review of Human Randomized Controlled Trial Studies and Recommendations for $\mathrm{Fu}-$ ture Studies," Genes \& Nutrition, Vol. 4, No. 4, 2009, pp. 227-242. http://dx.doi.org/10.1007/s12263-009-0135-4

[15] T. H. Crook, E. P. Feher and G. J. Larrabee, “Assessment of Memory Complaints in Age Associated Memory Impairment: The MAC-Q," International Psychogeriatrics, Vol. 4, No. 2, 1992, pp. 165-176. http://dx.doi.org/10.1017/S1041610292000991

[16] R. Norbury, W. L. Cutter, J. Compton, D. M. Robertson, M. Craig, et al., "The Neuroprotective Effects of Estrogen on the Aging Brain," Experimental Gerontology, Vol. 38, No. 1-2, 2003, pp. 109-117. http://dx.doi.org/10.1016/S0531-5565(02)00166-3

[17] D. Kritz-Silverstein, D. Von Muhlen, E. Barret-Connor and M. A. B. Bressel, "Isoflavones and Cognitive Function in Older Women: The Soy and Postmenopausal Health in Aging (SOPHIA) Study," Menopause, Vol. 10, No. 3, 2003, pp. 196-202. http://dx.doi.org/10.1097/00042192-200310030-00004

[18] S. E. File, D. E. Hartley, S. Elsabagh, R. Duffy and H. Wiseman, "Cognitive Improvement after 6 Weeks of Soy Supplements in Postmenopausal Women Is Limited to Frontal Lobe Function," Menopause, Vol. 12, No. 2, 2005, pp. 193-201. http://dx.doi.org/10.1097/00042192-200512020-00014

[19] H. Hachul, L. R. A. Bittencourt, J. M. Soares Jr., S. Tufik and E. C. Baracat, "Sleep in Postmenopausal Women: Dif- ferences between Early and Late Post-Menopause," European Journal of Obstetrics \& Gynecology and Reproductive Biology, Vol. 145, No. 1, 2009, pp. 81-84. http://dx.doi.org/10.1016/i.ejogrb.2009.03.019

[20] D. R. S. De Lorenzi, E. C. Baracat, B. Saciloto and J. R. I. Padilha, "Fatores Associados à Qualidade de vida após Menopausa," Revista da Associação Médica Brasileira, Vol. 52, No. 5, 2006, in press. http://dx.doi.org/10.1590/S0104-42302006000500017

[21] E. R. Alpizar and D. N. Despaigne, "Factores Relacionados con la Demanda de Atención Médica para el Climaterio," Revista Cubana de Endocrinología, Vol. 14, No. 3, 2003 , in press. http://bvs.sld.cu/revistas/end/vol14_3_03/end03303.htm

[22] R. L. Sousa, R. G. Filizola, M. F. F. Diniz, E. S. S. Sousa and J. L. R. Moraes, "Ensaio Clínico Placebo-Controlado com Isoflavonas da Soja," Revista Brasileira de Ginecologia e Obstetrícia, Vol. 28, No. 2, 2006, pp. 91-100. http://dx.doi.org/10.1590/S0100-72032006000200004

[23] J. B. Howes, K. Bray, L. Lorenz, P. Smerdely and L. G. Howes, "The Effects of Dietary Supplementation with Isoflavones from Red Clover on Cognitive Function in Postmenopausal Women," Climacteric, Vol. 7, No. 1, 2004, pp. 70-77. http://dx.doi.org/10.1080/13697130310001651490

[24] S. Kreijkamp-Kaspers, L. Kok, D. E. Grobbee, E. H. Haan, A. Aleman, J. W. Lampe and Y. T. Van der Schouw, "Effect of Soy Protein Containing Isoflavones on Cognitive Function, Bone Mineral Density, and Plasma Lipids in Postmenopausal Women: A Randomized Controlled Trial," JAMA, Vol. 292, No. 1, 2004, pp. 65-74. http://dx.doi.org/10.1001/jama.292.1.65

[25] S. C. Ho, A. S. Chan, Y. P. Ho, E. K. So, A. Sham, B. Zee and J. L. Woo, "Effects of Soy Isoflavone Supplementation on Cognitive Function in Chinese Postmenopausal Women: A Double-Blind, Randomized, Controlled Trial," Menopause, Vol. 14, No. 3, 2007, pp. 489-499.

[26] M. S. Beeri, J. Schmeidler, M. Sano, J. Wang, R. Lally and H. Grossman, "Age, Gender, and Education Norms on the CERAD Neuropsychological Baterry in the Oldest Old," Neurology, Vol. 67, No. 6, 2006, pp. 1006-1010. http://dx.doi.org/10.1212/01.wnl.0000237548.15734.cd 